\title{
Design of multi-target activity landscapes that capture hierarchical activity cliff distributions
}

\author{
Dilyana Dimova*, Jürgen Bajorath \\ From 7th German Conference on Chemoinformatics: 25 CIC-Workshop \\ Goslar, Germany. 6-8 November 2011
}

For compounds with activity against multiple targets the ensuing multi-target structure-activity relationships (mtSARs) are generally difficult to analyze. However, understanding $\mathrm{mtSARs}$ is often of critical importance for compound design and optimization [1]. In addition, the detection and analysis of activity cliffs also plays a crucial role in comprehensive SAR exploration $[2,3]$. Activity cliffs represent the most prominent feature of activity landscapes, which can be graphically represented by models that integrate molecular similarity and potency relationships $[2,4]$. Different activity landscape representations have been introduced. These activity landscape designs have in common that they all focus on activity against a single or at most two biological targets (the latter case giving rise to selectivity landscapes [3]). For compounds active against multiple targets, landscape representations cannot be obtained directly on the basis of currently available models and new design concepts are required. Here we introduce a methodology to derive and visualize multi-target activity landscapes and systematically analyze activity cliff distributions [5]. The framework is based on a general activity cliff classification scheme. Multi-target activity landscapes are visualized as graphs where nodes represent individual compounds and edges activity cliffs. In addition, node proximity indicates molecular similarity. The methodology has been applied to derive landscape models for various compound data sets with activity against multiple targets belonging to different families. The resulting representations identify single and multitarget activity cliffs and reveal hierarchical cliff distributions. From these landscape models, compounds forming complex activity cliffs can be readily selected.

Department of Life Science Informatics, B-IT, LIMES Program Unit Chemical Biology and Medicinal Chemistry, Rheinische Friedrich-Wilhelms-Universität, Dahlmannstr. 2, D-53113 Bonn, Germany
Published: 1 May 2012

\section{References}

1. Kubinyi H: Similarity and Dissimilarity. A Medicinal Chemist's View. Perspect Drug Discovery Des 1998, 9-11:225-252.

2. Maggiora GM: On Outliers and Activity Cliffs - Why QSAR Often Dissapoints. J Chem Inf Model 2006, 46:1535.

3. Bajorath J, Peltason L, Wawer M, Guha R, Lajiness MS, Van Drie JH: Navigating Structure-Activity Landscapes. Drug Discovery Today 2009, 14:698-705.

4. Wassermann AM, Wawer M, Bajorath J: Activity Landscape Representations for Structure-Activity Relationship Analysis. J Med Chem 2010, 53:8209-8223.

5. Dimova D, Wawer M, Wasserman AM, Bajorath J: A Design of Multitarget Activity Landscapes That Capture Hierarchical Activity Cliff Distributions. J Chem Inf Model 2011, 51:258-266.

doi:10.1186/1758-2946-4-S1-P4

Cite this article as: Dimova and Bajorath: Design of multi-target activity landscapes that capture hierarchical activity cliff distributions. Journal of Cheminformatics 2012 4(Suppl 1):P4.

\section{Publish with ChemistryCentral and every scientist can read your work free of charge \\ “Open access provides opportunities to our colleagues in other parts of the globe, by allowing anyone to view the content free of charge." \\ W. Jeffery Hurst, The Hershey Company. \\ - available free of charge to the entire scientific community \\ - peer reviewed and published immediately upon acceptance \\ - cited in PubMed and archived on PubMed Central \\ - yours - you keep the copyright \\ Submit your manuscript here: \\ http://www.chemistrycentral.com/manuscript/

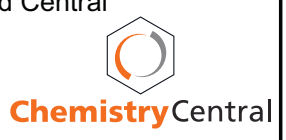

